\title{
A case of big omental cyst mimicking like malignant ovarian tumor
}

Keywords: omental, malignant, cyst, mimicking, uterus, ovaries, months, periods, menstrual, tumor

\section{Introduction}

30 year old female diagnosed a case of ovarian tumor on USG and CT scan and raised CA 125 (600). But on laparotomy there was a big omental cyst. Uterus and ovaries were normal. Omental cyst is very rare but sometime it confused with Ovarian Tumor. ${ }^{1-3}$

\section{Case detail}

30 year old with only one child presented with complain of swelling in abdomen for two months which was gradually increasing in size. She was also complaining of pain abdomen and nausea. There is no loss of weight. Her menstrual periods were regular. On examination there was mild pallor her pulse rare was $90 /$ minute. Her BP was $120 / 88 \mathrm{~mm}$ of $\mathrm{Hg}$. There was no lymphadenopathy mild pedal edema was present. On per abdominal examination there was a cystic lump in lower abdomen expending up to umbilicus. On per speculum examination cervix was normal. On per vaginal examination uterus could not be felt separately from mass. No tenderness. On Ultrasound

\author{
Volume 8 Issue I - 2019
}

\section{Anjali Rani, Heena, Poojita,Vivek Srivastava Department of Obstetrics and Gynecology, University Institute of Medical Sciences, India}

\begin{abstract}
Correspondence: Anjali Rani, Department of Obstetrics and Gynecology, University Institute of Medical Sciences, Varanasi, Uttar Pradesh, India, Tel 9936044220,

Email anjaliraniimsbhu@gmail.com
\end{abstract}

Received: March 01, 2017| Published: January 08, 2019

there was a large ovarian mass. CT scan was also done which was also showing large ovarian mass (Figure 1) (Figure 2). There was no ascites and no lymphadenopathy. Patient was planned for total abdominal hysterectomy and bilateral salpingoophrectomy. But patient was willing for preservation of her fertility because she wanted one more child. ${ }^{4}$

Figure I CT scan.
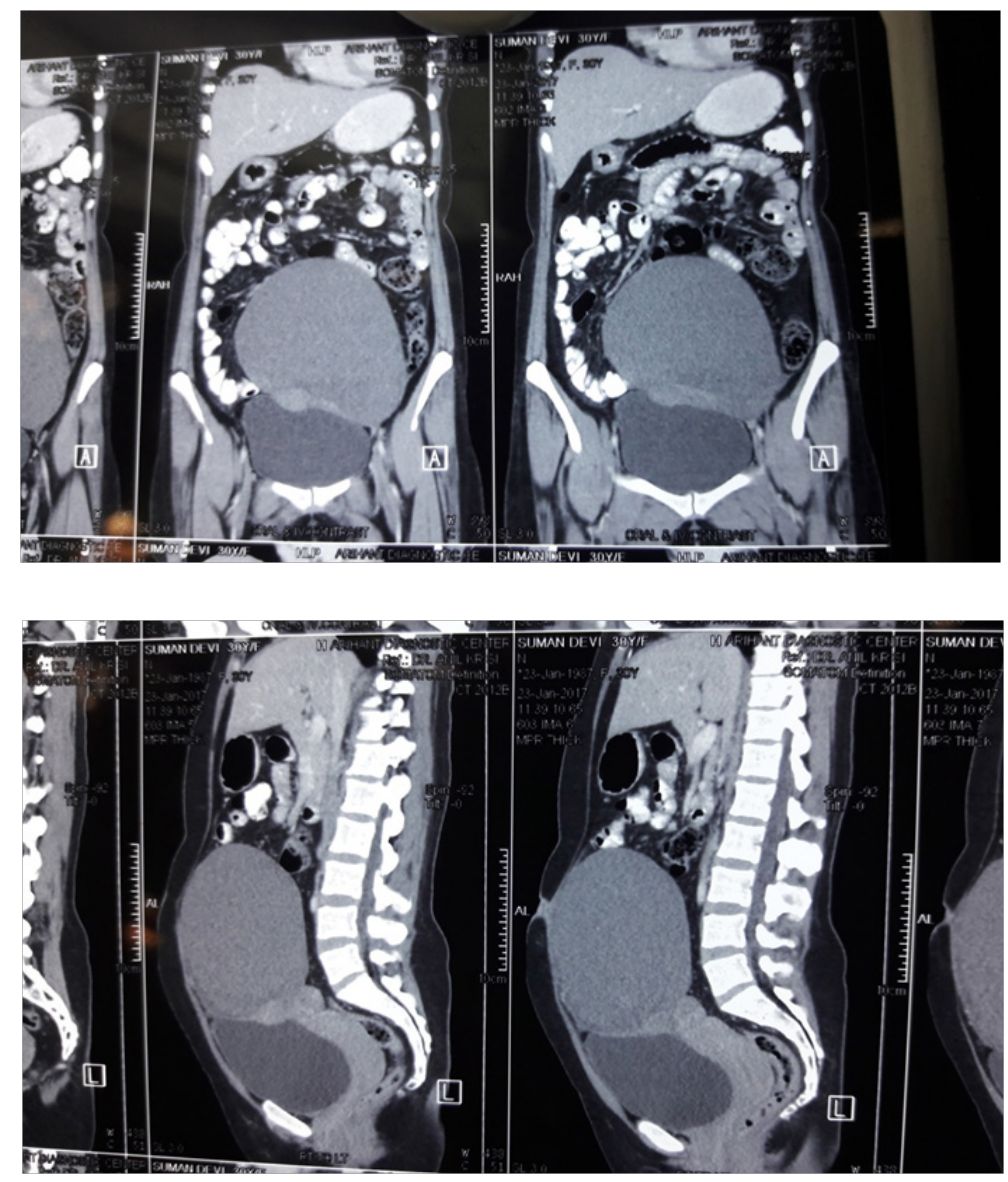

Figure 2 Showing ovarian tumor. 
On doing laparotomy the mass was not arising from ovary. Uterus and both ovaries were normal. The cystic mass was arising from omentum (Figure 3) ${ }^{5,6}$ So simple removal of omental cyst was done and omental biopsy taken. Postoperative period was uneventful.

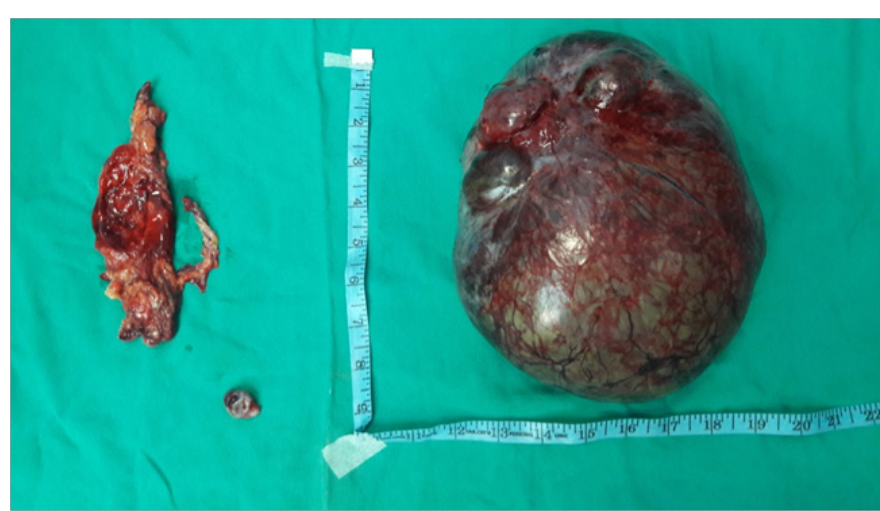

Figure 3 Showing omental cyst, omentum, and ovarian biopsy.

\section{Discussion}

Benign omental cyst is very uncommon. They can arise from greater or lesser omentum. They can be single or multiple. They contain serous or hemorrhagic or infected fluid. The cause of omental cyst is trauma, failure of lymphatic to join the venous system etc. But if it is big and present in pelvic region it can easily be mimic as ovarian tumor. Sometime it became good for the patient when we open it as malignant ovarian tumor and it come out to benign omental cyst.

\section{Conclusion}

The main aim of publishing this case report is that omental cyst can be one do the differential diagnosis of ovarian tumor.

\section{Acknowledgments}

None.

\section{Conflicts of interest}

The author declares there are no conflicts of interest.

\section{References}

1. Mani H, Merino MJ. Mesothelial neoplasms presenting as, and mimicking, ovarian cancer. Int J Gynecol Pathol. 2010;29(6):523-528.

2. Tao LC. Aspiration biopsy cytology of mesothelioma. Diagn Cytopathol. 1989;5(1):14-21

3. Testa AC, Zannoni GF, Ferrari S, et al. Benign cystic peritoneal mesothelioma incorrectly diagnosed as an ovarian borderline mucinous tumor of intestinal type at transvaginal preoperative ultrasound evaluation. Ultrasound Obstet Gynecol. 2011;37(2):248-250.

4. Shuji Takemoto, Ryosuke Kawano, Kazumi Honda, et al. Benign multicystic peritoneal mesothelioma mimicking recurrence of an ovarian borderline tumor: a case report. 2012. $126 \mathrm{p}$.

5. lu Devrim Karaosmanog, Oktar Suna O zhan, cel Cem Yu, et al. Huge omental cyst simulating ascites. European Journal of Radiology Extra. 2005;54(2):55-57

6. Kumar S, Agrawal N, Khanna R, Khanna AK. Giant lymphatic cyst omentum: a case report. Cases J. 2009:7(2):23-28. 